\title{
Treatment Options in Anthracycline and/or Taxane Pretreated Patients with Metastatic Breast Cancer
}

\author{
Lina Pugliano ${ }^{a, b}$ Evandro de Azambuja $a^{a, b}$ \\ aDepartment of Medicine,

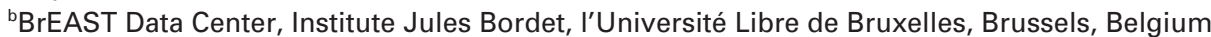

In developed countries nearly $30 \%$ of women with early stage breast cancer will eventually develop metastatic breast cancer (MBC), however, recent reports have demonstrated improvements in median survival mainly due to progresses made in treatment options [1,2]. The therapeutic management of these women is multifaceted, encompassing many issues including tumor factors (i.e., aggression of disease, tumor burden, sites of disease, estrogen receptor, and HER2 status), previous treatment factors (i.e., use of and responsiveness to prior therapies, and associated toxicities) and last but not least patient factors (i.e., menopausal status, performance status, comorbidities, psychological concerns, and patient preferences).

The phase II trial of mitomycin (MMC) and vinorelbine in patients with $\mathrm{MBC}$ pretreated with anthracycline and/or taxane, which appears in this month's issue of ONKOLOGIE [3], successfully focuses attention on the need for effective second and third-line regimens once anthracyclines and taxanes fail. The concept of anthracycline/taxane resistance is complicated by an assortment of patient populations and definitions in the clinical literature. Thus, Pivot et al. [4] put forward a series of definitions for anthracycline resistance applicable to other chemotherapeutics. These are associated with a statistically significant difference in survival from the date of progression with the median overall survival (OS) being 5 months for primary and secondary resistance, 9 months for progressive disease (PD) within 6 months after the last dose of anthracycline and 11 months for PD between 6 and 12 months after the last dose of anthracycline, clearly signaling the need for clarity of definitions in clinical trials of this nature.

Therapeutically, in this setting, capecitabine is approved by the US Food and Drug Administration (FDA) and the European Medicines Agency (EMA) and was endorsed by the 1st international consensus guidelines for advanced breast cancer (ABC1) [5]. It thus represents the international standard of care. A systematic review of 28 single-agent capecitabine trials revealed a median overall response rate (ORR) of $28 \%$ (range 9-53\%) with a median OS of 11.0 months (range 5.318.1 months). The advantages of capecitabine are well documented and include good efficacy, tolerability with minimal grade 3-4 toxicity, oral preparation, maintaining quality of life, and cost effectiveness [6].

Another commonly employed option is vinorelbine, which in anthracycline and taxane pretreated patients, yields response rates (RR) of $10-35 \%$ as a single agent and $25-61 \%$ in combinations with non-taxanes in anthracycline pretreated patients [7-17].

Newer agents, such as eribulin, have gained approval by the FDA and EMA in patients with prior anthracycline and taxane exposure. The Embrace trial (Eribulin to best physicians choice) in heavily pre-treated locally advanced or MBC patients revealed an ORR of 12.2 versus $4.7 \%(p=0.002)$, a progression free survival (PFS) of 3.7 versus 2.2 months (hazard ratio $(\mathrm{HR})=0.87,95 \%$ confidence interval $(\mathrm{CI})$ $=0.71-1.05, \mathrm{p}=0.137)$ and an of 13.1 versus 10.6 months (HR 0.81, 95\% CI $=0.61-0.99, \mathrm{p}=0.041)$ with a tolerable toxicity profile [18].

Additional agents include nab-paclitaxel, which in phase II trials produced RR of $15 \%$ in anthracycline and taxane pretreated patients and ixabepilone in combination with capecitabine [19, 20].

A further alternative may arise from the ongoing BEACON trial, a phase III, open-label, randomized, multicenter study of pegylated irinotecan versus physician's choice in $840 \mathrm{MBC}$ patients pre-treated with anthracycline, taxane, and capecitabine in the adjuvant or metastatic setting [21].

In the current study of MMC and vinorelbine, $65 \%$ of patients were pre-treated with anthracyclines and taxanes, but it is unclear how these patients are positioned within the Pivot et al. classifications. This notwithstanding, the ORR was $26 \%$ with a median PFS of 5.0 months (95\% CI $=3.6-6.8)$, comparable to other agents approved for this setting. We assume HER2 negativity though this is not described in the text, but alluded to in the conclusion.

\section{KARGER}

Fax +497614520714

Information@Karger.de

www.karger.com (c) 2012 S. Karger GmbH, Freiburg

0378-584X/12/0359-0476\$38.00/0

Accessible online at:

www.karger.com/onk
Evandro de Azambuja, MD

BrEAST Data Centre

Jules Bordet Institute

Boulevarde de Waterloo, 121 (7th Floor), 1000 Brussels, Belgium

Tel: +322 541-3509, Fax -3477

evandro.azambuja@bordet.be 
This trial emphasizes the controversial discussion of single agent versus combination chemotherapy for MBC patients. Evidence for both arguments exists in this well debated issue with a Cochrane review establishing a higher RR (OR for response $=1.28,95 \% \mathrm{CI}=1.15-1.42, \mathrm{p}<0.001)$, longer time to progression $(\mathrm{HR}=0.78,95 \% \mathrm{CI}=0.73-0.83, \mathrm{p}<0.001)$ and longer OS (HR for death $=0.88,95 \% \mathrm{CI}=0.83-0.94, \mathrm{p}<0.001$ ) for combination chemotherapy [22]. However, not all patients will derive benefits from combination therapy in MBC.

Conversely, these marginal benefits are offset by the toxicity associated with combination treatment. Additionally, these results are confounded by several factors blunting the effect of either arm. International guidelines identify single sequential chemotherapy and combination options as reasonable first-line choices [23]. In second or third-line settings, combination therapy is more contentious.

In the current study of MMC plus vinorelbine we observe rates of patient discontinuation $(14 \%)$ due to the well-established but rare dyspnea syndrome with MMC and vinorelbine, hematological toxicity and asthenia. This is comparable to rates with capecitabine (7-13\%), vinorelbine (5\%) and eribulin $(17 \%)$ [15, 18, 20, 24, 25]. The most significant effect of treatment is hematological toxicity with grade 3 or 4 neutropenia of $37 \%$ significantly higher than seen with capecitabine (1\%) [6]. Other combination strategies in this setting (e.g., gemcitabine/vinorelbine, ixabepilone/capecitabine) yield similar hematological toxicity, highlighting the consequences of combination treatment in pre-treated $\mathrm{MBC}[15,20]$.
MMC has been used in combination with vinblastine or vinorelbine in $\mathrm{MBC}$. In the present study, the authors choose a non-standard administration of MMC (3-h infusion) to minimize thrombocytopenia rates. Unfortunately, the rates of thrombocytopenia and the distribution by grade reported in trials using $\mathrm{MMC}+$ vinorelbine/vinblastine bolus are comparable to rates of the current trial [26-29]. Even administration as a 5-day infusion with 5-flurouracil results in thrombocytopenia rates of approximately $20 \%$, likely reflecting the natural toxicity profile of MMC rather than an administration effect [29].

The present article highlights that MBC patients are unique amongst metastatic cancer patients due to the multitude of agents that are active in breast cancer. While the toxicity profile of MMC plus vinorelbine indicates that this regimen may not be the first preference in anthracycline and taxane pretreated patients, older agents and their combinations should not be forgotten as potential therapeutic options in the enthusiasm for new agents. Also, the selection of patients to be treated with combination chemotherapy in the metastatic setting remains fundamental and should be agreed during the multidisciplinary team discussion.

\section{Disclosure Statement}

The authors declare no conflict of interests.

\section{References}

${ }_{1}$ O'Shaughnessy J: Extending survival with chemotherapy in metastatic breast cancer. Oncologist 2005;10(suppl 3):20-29.

2 Ruiterkamp J, Ernst MF, de Munck L, van der Heiden-van der Loo M, Bastiaannet E, van de PollFranse LV, Bosscha K, Tjan-Heijnen VC VA: Improved survival of patients with primary distant metastatic breast cancer in the period of 1995-2008. A nationwide population-based study in the Netherlands. Breast Cancer Res Treat 2011;28:495-503.

3 Schippert C, Warm M, Blohmer JU, du Bois A, Lück HJ: Mitomycin $\mathrm{C}$ in combination with vinorelbine in anthracycline and/or taxane-pretreated patients with metastatic breast cancer. Onkologie 2012;35: DOI: $10.1159 / 000341839$.

-4 Pivot X, Asmar L, Buzdar AU, Valero V, Hortobagyi G: A unified definition of clinical anthracycline resistance breast cancer. Br J Cancer 2000;82:529-534.

5 Cardoso F, Costa A, Norton L, Cameron D, Cufer T, Fallowfield L, Francis P, Gligorov J, Kyriakides S, Lin N, Pagani O, Senkus E, Thomssen C, Aapro M, Bergh J, Di Leo A, El Saghir N, Ganz PA, Gelmon K, Goldhirsch A, Harbeck N, Houssami N, Hudis C, Kaufman B, Leadbeater M, Mayer M, Rodger A, Rugo H, Sacchini V, Sledge G, Van't Veer L, Viale G, Krop I, Winer E: 1st International consensus guidelines for advanced breast cancer (ABC 1). Breast (Edinburgh, Scotland) 2012; DOI: 10.1016/j. breast.2012.03.003 6rshler WB: Capecitabine monotherapy: safe and effective treatment for metastatic breast cancer. Oncologist 2006;11:325-335.

7 Jara-Sánchez C, Martín M, García-Sáenz JA, Barnada A, Fernández-Aramburo A, LópezVega JM, Pelegrí A, Alba E, Casado A: Vinorelbine as a 96-hour continuous infusion in heavily pretreated patients with metastatic breast cancer: a cooperative study by the GEICAM group. Clin Breast Cancer 2003;3:399-404.

8 Pajk B, Cufer T, Canney P, Ellis P, Cameron D, Blot E, Vermorken J, Coleman R, Marreaud S, Bogaerts J, Basaran G, Piccart M: Anti-tumor activity of capecitabine and vinorelbine in patients with anthracycline- and taxane-pretreated metastatic breast cancer: findings from the EORTC 10001 randomized phase II trial. Breast (Edinburgh, Scotland) 2008;17:180-185.

9 Papaldo P, Fabi A, Ferretti G, Mottolese M, Cianciulli AM, Di Cocco B, Pino MS, Carlini P, Di Cosimo S, Sacchi I, Sperduti I, Nardoni C, Cognetti F: A phase II study on metastatic breast cancer patients treated with weekly vinorelbine with or without trastuzumab according to HER2 expression: changing the natural history of HER2positive disease. Ann Oncol 2006;17:630-636

10 Seo HY, Lee HJ, Woo OH, Park KH, Woo SU, Yang DS, Kim AR, Lee JB, Lee ES, Kim YH, Kim JS, Seo JH: Phase II study of vinorelbine monotherapy in anthracycline and taxane pre-treated metastatic breast cancer. Invest New Drugs 2011;29:360-365.
11 Toi M, Saeki T, Aogi K, Sano M, Hatake K, Asaga T, Tokuda Y, Mitsuyama,S, Kimura M, Kobayashi T, Tamura M, Tabei T, Shin E, Nishimura R, Ohno S, Takashima S: Late phase II clinical study of vinorelbine monotherapy in advanced or recurrent breast cancer previously treated with anthracyclines and taxanes. Jpn J Clin Oncol 2005;35:310-315.

12 Udom DI, Vigushin DM, Linardou H, Graham H, Palmieri C, Coombes RC: Two weekly vinorelbine: administration in patients who have received at least two prior chemotherapy regimes for advanced breast cancer. Eur J Cancer 2000;36:177-182.

13 Zelek L, Barthier S, Riofrio M, Fizazi K, Rixe O, Delord JP, Le Cesne A, Spielmann M: Weekly vinorelbine is an effective palliative regimen after failure with anthracyclines and taxanes in metastatic breast carcinoma. Cancer 2001;92:2267-2272.

14 Livingston RB, Ellis GK, Gralow JR, Williams MA, White R, McGuirt C, Adamkiewicz BB, Long CA:Dose-intensive vinorelbine with concurrent granulocyte colony-stimulating factor support in paclitaxel-refractory metastatic breast cancer. J Clin Oncol 1997;15:1395-1400.

15 Martín M, Ruiz A, Muñoz M, Balil A, GarcíaMata J, Calvo L, Carrasco E, Mahillo E, Casado A, García-Saenz JA, Escudero MJ, Guillem V, Jara C, Ribelles N, Salas F, Soto C, MoralesVasquez F, Rodríguez C, Adrover E, Mel JR: Gemcitabine plus vinorelbine versus vinorelbine monotherapy in patients with metastatic breast cancer previously 
treated with anthracyclines and taxanes: final results of the phase III Spanish Breast Cancer Research Group (GEICAM) trial. Lancet Oncol 2007;8:219-225.

16 Günel N, Akçali Z, Yamaç D, Onuk E, Yilmaz E, Bayram O, Tekin E, Co kun U: Cisplatin plus vinorelbine as a salvage regimen in refractory breast cancer. Tumori 2012;86:283-285.

17 Berruti A, Sperone P, Bottini A, Gorzegno G, Lorusso V, Brunelli A, Botta M, Tampellini M, Donadio M, Mancarella S, De Lena M, Alquati P, Dogliotti L: Phase II study of vinorelbine with protracted fluorouracil infusion as a second- or thirdline approach for advanced breast cancer patients previously treated with anthracyclines. J Clin Oncol 2000;18:3370-3377.

18 Cortes J, O'Shaughnessy J, Loesch D, Blum JL, Vahdat LT, Petrakova K, Chollet P, Manikas A, Diéras V, Delozier T, Vladimirov V, Cardoso F, Koh H, Bougnoux P, Dutcus CE, Seegobin S, Mir D, Meneses N, Wanders J, Twelves, C: Eribulin monotherapy versus treatment of physician's choice in patients with metastatic breast cance (EMBRACE): a phase 3 open-label randomised study. Lancet 2011;377:914-923.

19 Blum JL, Savin MA, Edelman G, Pippen JE, Robert NJ, Geister BV, Kirby RL, Clawson A O'Shaughnessy JA: Phase II study of weekly albumin-bound paclitaxel for patients with metastatic breast cancer heavily pretreated with taxanes. Clin Breast Cancer 2007;7:850-856.
20 Thomas ES, Gomez HL, Li RK, Chung H-C, Fein LE, Chan VF, Jassem J, Pivot XB, Klimovsky JV, de Mendoza FH, Xu B, Campone M, Lerzo GL, Peck RA, Mukhopadhyay P, Vahdat LT, Roché HH: Ixabepilone plus capecitabine for metastatic breast cancer progressing after anthracycline and taxane treatment. J Clin Oncol 2007;25:5210-5217.

21 Awada A, Zhao C, Hannah AL, Perez EA: The BEACON Study (BrEAst Cancer Outcomes With NKTR-102): A phase 3 open-label, randomized, multicenter study of NKTR-102 versus treatment of physician's choice (TPC) in patients with locally recurrent or metastatic breast cancer previously treated with an anthracycline, a taxane and capecitabine. San Antonio Breast Cancer Conference. 2011, Abstract \#OT3-01-07.

22 Carrick S, Parker S, Thornton CE, Ghersi D, Simes J, Wilcken N: Single agent versus combination chemotherapy for metastatic breast cancer. Cochrane database of systematic reviews (Online) 2009;CD003372.

23 Cardoso F, Bedard PL, Winer EP, Pagani O, Senkus-Konefka E, Fallowfield LJ, Kyriakides S, Costa A, Cufer T, Albain KS: International guidelines for management of metastatic breast cancer: combination vs sequential single-agent chemotherapy. JNCI 2009;101:1174-81.

24 Reichardt P, Von Minckwitz G, Thuss-Patience PC, Jonat W, Kölbl H, Jänicke F, Kieback DG, Kuhn W, Schindler AE, Mohrmann S, Kaufmann M, Lück HJ: Multicenter phase II study of oral capecitabine (Xeloda) in patients with metastatic breast cancer relapsing after treatment with a taxane-containing therapy. Ann Oncol 2003;14:1227-1233.
5 Geyer CE, Forster J, Lindquist D, Chan S, Romieu CG, Pienkowski T, Jagiello-Gruszfeld A, Crown J, Chan, A, Kaufman B, Skarlos D, Campone M, Davidson N, Berger M, Oliva C, Rubin SD, Stein S, Cameron D: Lapatinib plus capecitabine for HER2-positive advanced breast cancer. N Eng J Med 2006;355:2733-43.

26 Nabholtz JM, Senn HJ, Bezwoda WR, Melnychuk D, Deschênes L, Douma J, Vandenberg TA, Rapoport B, Rosso R, TrilletLenoir V, Drbal J, Molino A, Nortier JW, Richel DJ, Nagykalnai T, Siedlecki P, Wilking N, Genot JY, Hupperets PS, Pannuti F, Skarlos D, Tomiak EM, Murawsky M, Alakl M, Aapro M: Prospective randomized trial of docetaxel versus mitomycin plus vinblastine in patients with metastatic breast cancer progressing despite previous anthracycline-containing chemotherapy. 304 Study Group. J Clin Oncol 1999;17:1413-1424.

27 Scheithauer W, Kornek G, Haider K, Kwasny W, Schenk T, Pirker R, Depisch D: Effective second line chemotherapy of advanced breast cancer with navelbine and mitomycin C. Breast Cancer Res Treat 1993;26:49-53.

28 Vici P, Di Lauro L, Carpano S, Amodio A, Pignatti F, Casali A, Conti F, Lopez M: Vinorelbine and mitomycin $\mathrm{C}$ in anthracycline-pretreated patients with advanced breast cancer. Oncology 2012;53:16-18.

29 Hartmann JT, Harstrick A, Daikeler T, Kollmannsberger C, Müller C, Seeber S, Kanz L, Bokemeyer C: Phase II study of continuous $120 \mathrm{~h}$ infusion of mitomycin $\mathrm{C}$ as salvage chemotherapy in patients with progressive or rapidly recurrent colorectal cancer. Anticancer Drugs 1998;9:427-431. 